\title{
Monogenic diabetes: a gateway to precision medicine in diabetes
}

\author{
Haichen Zhang, ${ }^{1}$ Kevin Colclough, ${ }^{2}$ Anna L. Gloyn, ${ }^{3,4}$ and Toni I. Pollin' \\ 'University of Maryland School of Medicine, Department of Medicine, Baltimore, Maryland, USA. ${ }^{2}$ Exeter Cenomics Laboratory, Royal Devon and Exeter Hospital, Exeter, United Kingdom. ${ }^{3}$ Department of \\ Pediatrics, Division of Endocrinology, and ${ }^{4}$ Stanford Diabetes Research Center, Stanford School of Medicine, Stanford, California, USA.
}

\begin{abstract}
Monogenic diabetes refers to diabetes mellitus (DM) caused by a mutation in a single gene and accounts for approximately $1 \%-5 \%$ of diabetes. Correct diagnosis is clinically critical for certain types of monogenic diabetes, since the appropriate treatment is determined by the etiology of the disease (e.g., oral sulfonylurea treatment of HNF1A/HNF4A-diabetes vs. insulin injections in type 1 diabetes). However, achieving a correct diagnosis requires genetic testing, and the overlapping of the clinical features of monogenic diabetes with those of type 1 and type 2 diabetes has frequently led to misdiagnosis. Improvements in sequencing technology are increasing opportunities to diagnose monogenic diabetes, but challenges remain. In this Review, we describe the types of monogenic diabetes, including common and uncommon types of maturityonset diabetes of the young, multiple causes of neonatal DM, and syndromic diabetes such as Wolfram syndrome and lipodystrophy. We also review methods of prioritizing patients undergoing genetic testing, and highlight existing challenges facing sequence data interpretation that can be addressed by forming collaborations of expertise and by pooling cases.
\end{abstract}

\section{Introduction}

Monogenic diabetes is caused by a single defect in one of over 40 genes $(1,2)$. Since maturity-onset diabetes of the young (MODY) was named by Fajans for the type 2 diabetes-like presentation in young people with an autosomal dominant pattern of inheritance $(3,4)$, our understanding of phenotypic and genetic heterogeneity in monogenic diabetes has increased. The major monogenic diabetes categories are MODY, neonatal diabetes mellitus (NDM), and syndromic diabetes (5). Misdiagnosis is frequent because of overlapping of phenotypes with type 1 diabetes (T1D), such as young onset and leanness, and with type 2 diabetes (T2D), such as preserved $\beta$ cell function and family history. Tailored treatment of some monogenic diabetes depends on the disease's underlying etiology - e.g., oral sulfonylurea treatment of HNF1A/ HNF4A-MODY - and requires genetic testing to diagnose. Here we will describe monogenic diabetes types, etiologies, diagnosis, management, and strategies to improve diagnosis.

\section{Monogenic versus polygenic diabetes}

Monogenic and polygenic diabetes are traditionally considered distinct, with monogenic diabetes resulting from one highly penetrant variant in one gene in a given individual and polygenic diabetes resulting from the contribution of several variants with smaller effects in the context of environmental/lifestyle factors. In T1D, autoimmune dysfunction is the prominent mechanism, with variation in the major histocompatibility locus and other genomic

Conflict of interest: ALG's spouse is an employee of Genentech and holds stock and stock options in Roche. TIP receives research and salary support from the Regeneron Genetics Center and Regeneron Pharmaceuticals.

Copyright: (c) 2021, American Society for Clinical Investigation.

Reference information: J Clin Invest. 2021;131(3):e142244.

https://doi.org/10.1172/JCl142244. factors combining with apparent environmental triggers to result in $\beta$ cell loss and diabetes. In monogenic diabetes, highly penetrant variants, mostly causing extremely impaired $\beta$ cell development and insulin secretion, cause diabetes regardless of other risk factors. T2D, sometimes considered a diagnosis of exclusion, is a heterogeneous group of disorders involving smaller genetic effects on multiple mechanisms, including insulin secretion and insulin sensitivity, combining with environmental and lifestyle factors, mostly impacting insulin sensitivity. While this distinction is important both scientifically and clinically, emerging studies of the genetic architecture of diabetes reveal more of a spectrum with respect to the penetrance of genetic variants and their relative role in diabetes. For example, the $H N F 4 A$ variant p.R114W, found in $0.02 \%$ of non-Finnish Europeans, has been shown to be overrepresented in patients with MODY $(\mathrm{OR}=30.4$ vs. public variant databases) but to have a distinct clinical phenotype (including lack of sulfonylurea response) and much lower penetrance than other HNF4A MODY mutations ( $54 \%$ vs. $71 \%$ by age 30 ; ref. 6 ). In Mexican Americans, HNF1A variant p.E508K (NM_000545.8, rs 483353044) was associated with T2D with a much greater effect size $(\mathrm{OR}=4.2)$ than most polygenic $\mathrm{T} 2 \mathrm{D}$ variants, with diabetic carriers and noncarriers having similar onset age and BMI (7). T2D polygenic risk scores have also shown evidence of modifying age at diagnosis of monogenic diabetes (8). Finally, while lack of features of either autoimmunity or obesity/metabolic syndrome raises the likelihood of monogenic diabetes, these features can coexist with monogenic diabetes - particularly obesity, given its high prevalence especially in youth. In the Treatment Options for Diabetes in Adolescents and Youth (TODAY) clinical trial, in which overweight or obesity was required for enrollment of newly diagnosed youth with $\mathrm{T} 2 \mathrm{D}$, at least $4.5 \%$ were identified as having MODY. Those with HNF4A-MODY had poor response to metformin, representing a previously missed opportunity for optimal 
Table 1. Genetic causes of maturity-onset diabetes of the young

\begin{tabular}{|c|c|c|c|c|c|}
\hline $\begin{array}{l}\text { Gene/MODY number } \\
\text { (OMIM number) }\end{array}$ & Age of onset & Treatment & Distinguishing features & Pathophysiology & References \\
\hline PDX1/MODY4 (606392) & Young adulthood & $\mathrm{OHA}$ or insulin & $\begin{array}{l}\text { Pancreatic agenesis in homozygotes/ } \\
\text { compound heterozygotes (rare) }\end{array}$ & $\begin{array}{l}\text { Transcription factor defect disrupting } \\
\beta \text { cell development and function }\end{array}$ & $\begin{array}{c}16 \\
141-144\end{array}$ \\
\hline HNF1B/MODY5 (137920) & $\begin{array}{l}\text { Preadolescence to } \\
\text { young adulthood }\end{array}$ & Insulin & $\begin{array}{l}\text { Renal structural abnormalities, genital tract } \\
\text { malformations, pancreatic hypoplasia, } \\
\text { hypomagnesemia, abnormal liver function, } \\
\text { intellectual disabilities }\end{array}$ & $\begin{array}{c}\text { Transcription factor defect disrupting } \\
\beta \text { cell and renal cell development } \\
\text { and function }\end{array}$ & 56 \\
\hline INS/MODY10 (176730) & $\begin{array}{l}\text { Childhood to } \\
\text { young adulthood }\end{array}$ & Diet or insulin & $\begin{array}{l}\text { Specific mutations cause insulin dependence } \\
\text { due to ER stress-mediated } \beta \text { cell apoptosis }\end{array}$ & $\begin{array}{l}\text { Proinsulin misfolding and ER stress or } \\
\text { impaired insulin activity }\end{array}$ & $\begin{array}{c}76 \\
149-154\end{array}$ \\
\hline ABCC8/MODY12 (600509) & $\begin{array}{l}\text { Preadolescence to } \\
\text { young adulthood }\end{array}$ & Sulfonylureas & Neurological abnormalities in some cases & $\begin{array}{l}\text { Gain of function } \beta \text { cell ATP-sensitive } \\
\text { potassium channel defect }\end{array}$ & $\begin{array}{c}76,153 \\
154\end{array}$ \\
\hline KCN/11/MODY13 (616329) & Childhood & Sulfonylureas & Neurological abnormalities in some cases & $\begin{array}{l}\text { Gain of function } \beta \text { cell ATP-sensitive } \\
\text { potassium channel defect }\end{array}$ & $\begin{array}{c}76,146-148, \\
153,154\end{array}$ \\
\hline RFX6 & Varies & Diet, insulin, or $\mathrm{OHA}$ & Reduced penetrance for diabetes & $\begin{array}{l}\text { Transcription factor defect disrupting } \\
\beta \text { cell function }\end{array}$ & 11 \\
\hline
\end{tabular}

$B L K, P A X 4$, and KLF11, although classified as MODY genes (\#11, \#9, and \#7, respectively) in OMIM, are not listed as MODY-causing because of recently disputed or refuted gene-disease relationships (see "Rare MODY-classified monogenic diabetes types" in the main text). APPL1 was proposed as MODY14 based on two families reported in 2015 (42), but evidence is otherwise limited. RFX6 does not have a MODY number in OMIM, but is included here as multiple loss-of-function variants were recently implicated in a phenotype very similar to that of other MODY genes but with lower penetrance (11). OHA, oral hypoglycemia agents.

treatment (9). In summary, monogenic and polygenic forms of diabetes exist along more of a continuum than previously appreciated. Therefore, knowledge about monogenic diabetes not only provides opportunities for etiology-based treatment of the minority of individuals with highly penetrant variants, but also informs broader understanding of diabetes etiology.

\section{Types of monogenic diabetes}

\section{Maturity-onset diabetes of the young}

MODY comprises most monogenic diabetes cases, with classical characteristics of young diagnosis age, family history of diabetes in an autosomal dominant pattern of transmission, and insulin independence, with some types having additional features (Table 1). While 14 genes have now been designated as MODY genes in OMIM and/or the literature, three of these (BLK, PAX4, and KLF11) have been proposed for elimination based on a recent study (10) (see Table 1 for the remaining 11 along with RFX6, recently proposed as an additional MODY gene; ref. 11). Variants in GCK, HNF1A, and HNF4A are responsible for most MODY cases, followed by $H N F 1 B$ (12). Given the known genetic etiology of most MODY cases and the increased frequency of pediatric T2D due to increased childhood overweight and obesity prevalence, it has been suggested that this term be abandoned in favor of terms describing the etiology of the type of diabetes, such as transcription factor diabetes for MODY caused by mutations in the transcription factor genes $H N F 1 A, H N F 4 A, H N F 1 B$, and others (13). Moreover, it can be argued that any diabetes designation is unsuitable for the usually benign condition of heterozygous GCK deficiency, which is characterized by only mildly elevated glucose levels often not reaching the diabetic range and, more to the point, generally does not lead to diabetic micro- and macrovascular complications (14).

\section{Common types of MODY-classified monogenic diabetes}

HNF1A-MODY and HNF4A-MODY are caused by variants in genes encoding HNF1 homeobox A and hepatic nuclear factor $4 \alpha$, respectively. These transcription factors play essential roles in transcription of genes related to $\beta$ cell development and insulin secretion. HNF1A variants decrease expression of HNF1A target genes (15). Among patients diagnosed with diabetes, HNF1A-MODY is the most common MODY. To date, over $400 H N F 1 A$ variants and 100 $H N F 4 A$ variants have been discovered from MODY families (16). 
$H N F 1 A / H N F 4 A$-MODY is usually diagnosed in adolescence or early adulthood. Compared with T2D, HNF1A-MODY and HNF4A-MODY occur at younger ages with lower BMI, lower hemoglobin $\mathrm{A}_{1 \mathrm{c}}$ and triglycerides, and similar risk for microvascular complications. Approximately $50 \%$ of patients with HNF4A-MODY are macrosomic, which is attributed paradoxically to transient neonatal hyperinsulinemic hypoglycemia at birth (17). Hyperinsulinemic hypoglycemia was also recently observed in some patients with $H N F 1 A$-MODY (18).

Individuals with $H N F 1 A$ - and $H N F 4 A$-diabetes have increased sensitivity to sulfonylureas, an insulin-stimulating class of drug $(19,20)$, such that low doses are effective, and more typical T2D doses cause hypoglycemia. Sulfonylureas bind to the subunit of the $\mathrm{K}_{\mathrm{ATP}}$ channel to depolarize the $\beta$ cell and release insulin. In a randomized clinical trial, low doses of sulfonylureas (e.g., 20-40 mg gliclazide daily) produced better glucose control than metformin in HNF1A- and HNF4A-MODY (21). In an observational study, most patients with presumed T1D who were subsequently found to have HNF1A-diabetes gained glycemic control when treatment was changed from insulin to sulfonylureas (19). Glucagon-like peptide-1 receptor agonist monotherapy (22) or sulfonylurea in combination with dipeptidyl peptidase-4 inhibitor (23) was recently demonstrated to achieve good glycemic control in HNF1A-MODY with reduced or no hypoglycemia, suggesting possible utility as a first-line $H N F 1 A / H N F 4 A$-diabetes treatment.

$G C K$ encodes glucokinase, an enzyme catalyzing glucose phosphorylation at glycolysis initiation. GCK is a pancreatic $\beta$ cell glucose sensor; genetic defects change the glucose-stimulated insulin secretion threshold $(24,25)$. In the United Kingdom, the prevalence of GCK-hyperglycemia was estimated at $0.1 \%$ among White Europeans (26) - higher than that of HNF1A-diabetes because the lack of symptoms keeps many cases from coming to medical attention. Further studies are needed in other populations. GCK-hyperglycemia has limited phenotypic heterogeneity; most patients have lifelong mild, persistent, and asymptomatic fasting hyperglycemia within the prediabetes range (27), with hemoglobin $A_{1 c}$ values not exceeding 7.5\% $(60 \mathrm{mmol} / \mathrm{mol}$; ref. 28 ), though some have glucose levels that meet the diabetes mellitus (DM) criteria, and a few have T2D and related complications, likely due to additional genetic and environmental risk factors $(29,30)$. Glucose levels are resistant to lowering by insulin or oral agents. Moreover, since GCK-hyperglycemia does not appear to be associated with significant microvascular and macrovascular diabetes complications $(14,31)$, patients with GCK-hyperglycemia usually do not require glucose-lowering medication, except possibly during pregnancy. Maternal GCK mutations increase risk for macrosomia and associated perinatal complications similarly to gestational or pre-gestational diabetes of any type owing to the excess insulin secretion in response to a hyperglycemic intrauterine environment. Fetal GCK mutations decrease birthweight as a result of poor insulin response. A paternally inherited fetal mutation places the fetus at risk for low birthweight in a normoglycemic intrauterine environment. A maternal mutation creates a hyperglycemic intrauterine environment for fetal insulin secretion needed for normal growth of a GCK-deficient fetus, and thus attempts at normalizing maternal glucose may result in harm. In pregnant women with GCK mutations, it is recommended that, at minimum, fetal growth be monitored by serial ultrasound to guide treatment, but it is ideal to know the fetal mutation status early in pregnancy (32). A noninvasive technique for determining fetal GCK mutation status from cell-free DNA in maternal circulation is being developed that will enable women with a mutation-positive fetus to be discharged from high-risk antenatal care (33).

$H N F 1 B$ variants are estimated to account for less than $1 \%$ of MODY (34). Patients with HNF1B defects may exhibit early-onset DM only; diabetes with renal, pancreas, or liver phenotypes (renal cysts and diabetes [RCAD] syndrome); or other features with or without diabetes, such as neurodevelopmental disorders $(35,36)$ and hypomagnesemia. HNF1B genotype-phenotype correlation is currently unclear, with clinical heterogeneity even among family members with the same variant. However, renal outcome as measured by estimated glomerular filtration rate has been reported to be better in deletion versus nondeletion variants $(36,37)$; this is hypothesized to result from a dominant-negative effect (38, 39). Some $H N F 1 B$-MODY initially responds to sulfonylurea or repaglinide (36) but may ultimately require insulin.

\section{Rare MODY-classified monogenic diabetes types}

ATP-sensitive potassium channel $\left(K_{A T P}\right.$ channel) diabetes. Pathogenic variants in $A B C C 8$ and KCNJ11, the genes encoding sulfonylurea receptor 1 (SUR1) and the inward rectifier potassium channel 11 (Kir6.2), subunits of the ATP-sensitive potassium channel ( $\mathrm{K}_{\text {ATP }}$ channel) found in $\beta$ cells (Figure 1 ), are common causes of NDM (either permanent or transient; see below) but also can occasionally cause diabetes with later childhood or young adult onset (sometimes referred to as MODY12 [ref. 40] and MODY13 [ref. 41], respectively). $\mathrm{K}_{\text {ATP }}$ diabetes is discussed further in the NDM section below.

The prominent and rarer types of MODY and their genetic and clinical features are summarized in Table 1. Emerging findings obtained through next-generation sequencing (NGS) to identify new causes of MODY have suggested potential roles of APPL1 (42) and PCBD1 (43) in MODY.

\section{Neonatal DM}

NDM is defined as diabetes diagnosed within the first 6 months of age and can be either permanent (PNDM) or transient (TNDM). Clinical features of NDM also include intrauterine growth retardation, failure to thrive, polyuria, and severe dehydration (44, 45). Depending on the genetic etiology, some patients can also have birth defects and neurological disorders (46). It affects 1 in 90,000 to 260,000 live births $(47,48), 50 \%$ being PNDM and $50 \%$ being TNDM (44).

The diabetes phenotype in TNDM results from inadequate insulin production presenting at the first week of life and resolving by 18 months (44), but $50 \%$ of patients relapse during early adulthood (46). Approximately $60 \%-70 \%$ of TNDM is caused by overexpression of paternally expressed imprinted genes on chromosome 6q24 (hereafter referred to as 6q24-TNDM) resulting from paternally inherited duplications or paternal disomy for the region or chromosome (both copies inherited from the father; ref. 49). The remaining cases mostly result from mutations in $\mathrm{K}_{\text {ATP }}$ channels, KCNJ11 (50) and ABCC8 (51), which tend to be functionally less severe than those causing PNDM (52). There are also 


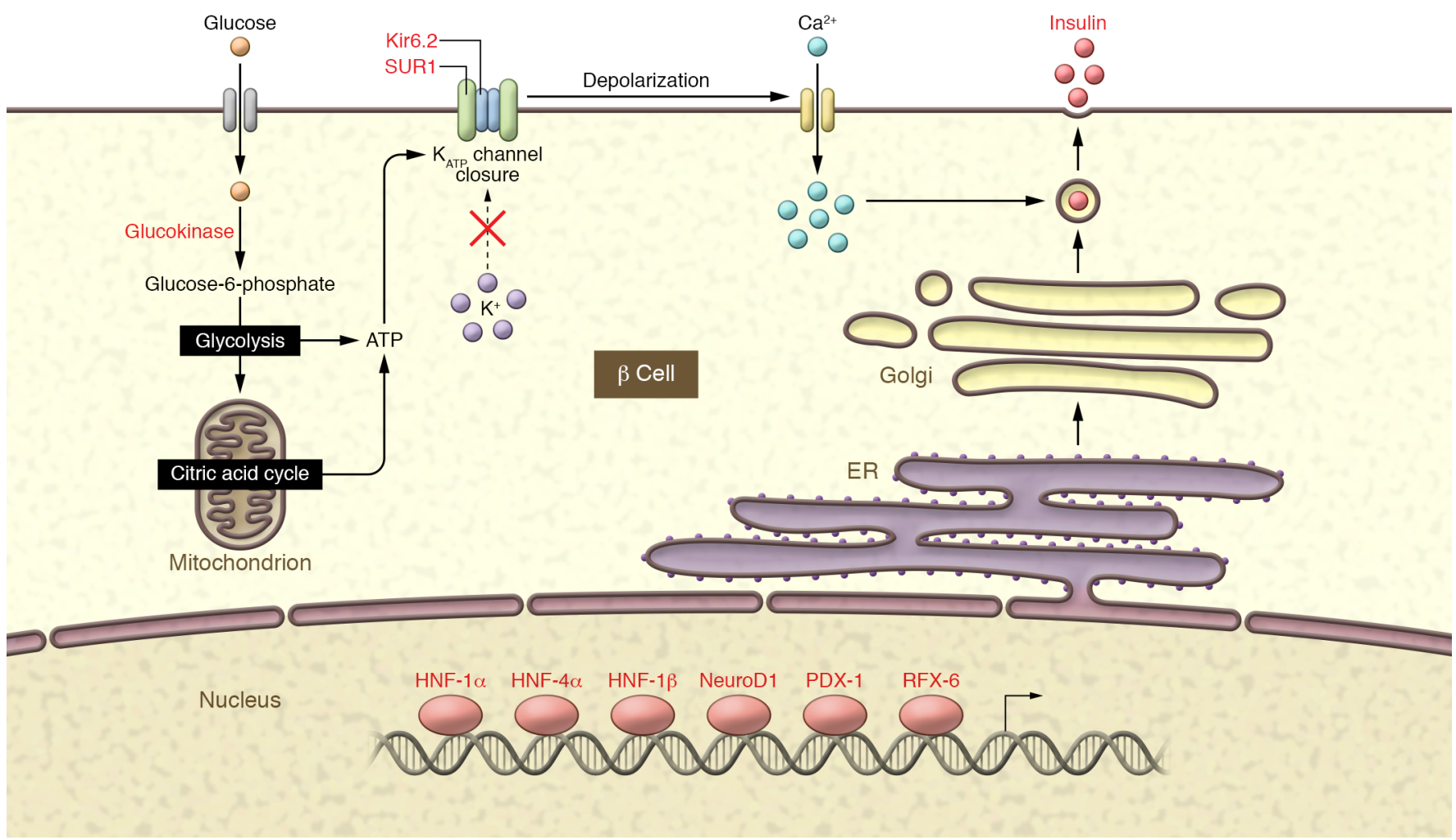

Figure 1. Schematic representation of glucose-induced insulin secretion and MODY-associated genes. The pancreatic $\mathrm{K}_{\text {ATP }}$ channel directly regulates insulin secretion. It is a hetero-octamer formed by four subunits of the inward rectifier potassium channel 11 (Kir6.2, encoded by KCNJ11) and four sulfonylurea receptor 1 (SUR1, encoded by $A B C C 8$ ) subunits. Glucose enters the $\beta$ cell and glucokinase phosphorylates glucose to glucose-6-phosphate, which further breaks down in the glycolysis and citric acid cycle to produce ATP. The increased ATP/MgATP ratio leads to the closure of the $\mathrm{K}_{\text {ATP }}$ channel and causes depolarization of the $\beta$ cell membrane and subsequent activation of voltage-gated calcium channels. Calcium flows into the cell through activated voltage-gated calcium channel and triggers the insulin to be released from the $\beta$ cell. Transcription factors (HNF1A, HNF4A, HNF1B, NEUROD1, PDX1, and RFX6) constitute a network that regulates the expression of insulin and $\beta$ cell development and proliferation. The MODY-associated genes are labeled in red.

rare occurrences attributed to mutations in INS (encoding the insulin precursor molecule preproinsulin; refs. 51, 53, 54), HNF1B $(55,56)$, and other genes (Table 2$)$. It remains undetermined why only some TNDM patients relapse later, but theories about $\beta$ cell function and the development of insulin resistance at puberty represent possible explanations (57).

Some of the same genes implicated in TNDM, including ABCC8, $K C N J 11$, and INS, also have variants that more commonly cause PNDM. Homozygous or compound heterozygous inactivating GCK mutations cause PNDM (ref. 25 and Table 2). PNDM can also be part of IPEX (immune dysregulation, polyendocrinopathy, enteropathy, $\mathrm{X}$-linked) syndrome, caused by variants in the FOXP3 gene; WolcottRallison syndrome, caused by variants in EIF2AK3; and others (58). Unlike more common types of PNDM, the PNDM of IPEX syndrome (and a few other rare types of monogenic diabetes; refs. 59, 60) is autoimmune, as FOXP3 is crucial in maintaining regulatory T cells' normal function of inhibiting proliferation and cytokine production of other T cells (61). PNDM in Wolcott-Rallison syndrome is possibly due to increased pancreatic $\beta$ cell apoptosis that is regulated by EIF2AK3 (62). Genes implicated in NDM and associated phenotypes are listed in Table 2 . Since a genetic cause has been identified in only $82 \%$ of patients with NDM (63), the search continues through exome sequencing, most recently implicating YIPF5 in autosomal recessive neonatal diabetes and microcephaly (64).
It is recommended that patients diagnosed with diabetes in the first 6 months of life obtain immediate genetic testing to identify the subtype, since T1D is extremely rare in this subgroup. Approximately $80 \%-85 \%$ of NDM cases have an identifiable genetic cause (63), half of these being $\mathrm{K}_{\text {ATP }}$-diabetes caused by KCNJ11 or ABCC 8 mutations, treatable with high-dose sulfonylureas rather than insulin $(50,65,66)$. The benefit of identifying patients with $\mathrm{K}_{\text {ATP }}$ diabetes is thus considerable, and many studies have attempted to establish genotype-phenotype correlation (67) to facilitate the prediction of patients' clinical courses based on genetic data.

NDM caused by pathogenic variants in $K_{A T P}$ channels. Activating $\mathrm{K}_{\mathrm{ATP}}$ channel gene variants cause NDM by decreasing ATP's ability to achieve channel closure in multiple ways (68). Whether variants will cause PNDM or TNDM (or, rarely, MODY) is determined in part by the functional severity of the mutation as well as which gene is involved, with KCNJ11 variants mainly associated with PNDM and most ABCC8 variants linked to TNDM $(51,69)$. Diabetes severity could be partially explained by the extent to which the variant impacts ATP sensitivity (70); however, the same variant in one family could cause both NDM and MODY in different patients (e.g., the KCNJ11 C42R variant; ref. 71), suggesting that other mechanisms influence the development of clinical presentation. Lossof-function (LOF) mutations in both genes cause an increase in insulin secretion and present as congenital hyperinsulinemic hypo- 
Table 2. Genetic causes of neonatal diabetes with current ISPAD testing guidelines

\begin{tabular}{|c|c|c|c|c|c|}
\hline Gene & Phenotype & Inheritance & Other features & Pathophysiology & Reference \\
\hline$A B C C 8$ & PNDM, TNDM & $A D$ & Developmental delay, epilepsy (DEND) & $\beta$ Cell dysfunction & $76,153,154$ \\
\hline EIF2AK3 & PNDM & AR & Wolcott-Rallison syndrome & $\beta$ Cell destruction & 62 \\
\hline FOXP3 & IPEX & $\mathrm{XLR}$ & IPEX syndrome & $\beta$ Cell destruction & 61 \\
\hline GATA4 & PNDM, TNDM & $A D$ & $\begin{array}{l}\text { Pancreatic agenesis, congenital cardiac defects, } \\
\text { developmental delay, neurocognitive defects }\end{array}$ & Abnormal pancreatic development & 155 \\
\hline GATA6 & PNDM & $A D$ & $\begin{array}{c}\text { Pancreatic agenesis, congenital cardiac defects, congenital } \\
\text { biliary tract anomalies }\end{array}$ & Abnormal pancreatic development & 156,157 \\
\hline GCK & PNDM & AR & & $\beta$ Cell dysfunction & $25,158-160$ \\
\hline GLIS3 & PNDM & AR & Congenital hypothyroidism, IUGR, polycystic kidney disease & Abnormal pancreatic development & $161-163$ \\
\hline HNF1B & PNDM, TNDM & $A D$ & Pancreatic hypoplasia and renal cyst & Abnormal pancreatic development & 55,56 \\
\hline IER3IP1 & PNDM & AR & Microcephaly, simplified gyral pattern, severe epilepsy & $\beta$ Cell destruction & 164 \\
\hline INS & PNDM, TNDM & $A D, A R$ & & $\beta$ Cell destruction & $53,150-152,166-170$ \\
\hline KCN]11 & PNDM, TNDM & $A D$ & Developmental delay, epilepsy (DEND) & $\beta$ Cell dysfunction & $76,153,154$ \\
\hline MNX1 & PNDM & AR & $\begin{array}{l}\text { Developmental delay, sacral agenesis, imperforate anus, } \\
\text { IUGR }\end{array}$ & Abnormal pancreatic development & 170 \\
\hline NEUROD1 & PNDM & AR & $\begin{array}{c}\text { Developmental delay, cerebellar hypoplasia, sensorineural } \\
\text { deafness, and visual impairment }\end{array}$ & $\beta$ Cell dysfunction & 145 \\
\hline NEUROG3 & PNDM & $A R$ & Malabsorptive diarrhea & Abnormal pancreatic development & $171-173$ \\
\hline NKX2-2 & PNDM & AR & $\begin{array}{l}\text { Developmental delay, hypotonia, short stature, deafness, } \\
\text { constipation }\end{array}$ & Abnormal pancreatic development & 170 \\
\hline PAX6 & PNDM & AR & Brain anomalies, microphthalmia & Abnormal pancreatic development & $174-176$ \\
\hline PDX1 & PNDM & AR & Pancreatic agenesis (common) & $\beta$ Cell dysfunction & $141,142,177-182$ \\
\hline $\begin{array}{l}\text { PLAGL1/ } \\
\text { HYMAI }\end{array}$ & TNDM & Imprinting & Macroglossia, umbilical hernia & Abnormal pancreatic development & 183 \\
\hline PTF1A & PNDM & AR & Pancreatic agenesis, cerebellar agenesis & Abnormal pancreatic development & $184-186$ \\
\hline$R F \times 6$ & PNDM & AR & $\begin{array}{c}\text { Pancreatic hypoplasia, intestinal atresia, and gallbladder } \\
\text { aplasia or hypoplasia (Mitchell-Riley syndrome) }\end{array}$ & Abnormal pancreatic development & $187-190$ \\
\hline SLC2A2 & PNDM & $A R$ & Fanconi-Bickel syndrome & $\beta$ Cell dysfunction & 191 \\
\hline SLC19A2 & PNDM & AR & Rogers syndrome & $\beta$ Cell dysfunction & 192 \\
\hline WFS1 & PNDM & $A D, A R$ & Wolfram syndrome & $\beta$ Cell destruction & 94,95 \\
\hline ZFP57 & TNDM & AR & $\begin{array}{c}\text { IUGR, microglossia, facial dysmorphism, cardiac anomalies, } \\
\text { umbilical hernia, and developmental delay }\end{array}$ & Abnormal pancreatic development & 193 \\
\hline
\end{tabular}

The Exeter Genomics Laboratory (Royal Devon and Exeter NHS Foundation Trust and University of Exeter Medical School, Exeter, United Kingdom) maintains an up-to-date, annotated list of genes sequenced for monogenic diabetes (Diabetes Genes website; https://www.diabetesgenes.org/testsfor-diabetes-subtypes), which currently includes 71 genes, including some with putative/research status, of which 35 have been evaluated for neonatal diabetes, including those listed here. In addition to MODY and NDM genes, the list also contains genes for syndromic subtypes diagnosed outside of the neonatal period. AD, autosomal dominant; AR, autosomal recessive; IUGR, intrauterine growth restriction; PNDM, permanent neonatal DM; TNDM, transient neonatal $\mathrm{DM}$; XLR, $\mathrm{X}$-linked recessive.

glycemia when found in the homozygous or compound heterozygous state $(72,73)$ and when dominant LOF mutations are found in the heterozygous state. In addition, paternally inherited recessive LOF mutations in combination with somatic loss of maternal 11p15.5 chromosomal region cause focal hyperinsulinism (74).

$\mathrm{K}_{\mathrm{ATP}}-\mathrm{NDM}$ is autosomal-dominantly inherited but often $(60 \%-84 \%)$ arises de novo $(75,76)$. Some individuals with NDM have neurological features in addition to DM (77), as $\mathrm{K}_{\mathrm{ATP}}$ channels are expressed in other tissues, including muscle and brain. Common $\mathrm{K}_{\text {ATP }}$-NDM features include muscle weakness, developmental delay, and early-onset epilepsy (DEND syndrome), while those with intermediate DEND (iDEND) syndrome do not have epilepsy (78). Treatment of $\mathrm{K}_{\text {ATP }}$-NDM caused by either KCNJ11 or $A B C C 8$ variants with high-dose sulfonylureas has proven safe and effective for both short-term and long-term glycemic control and may resolve CNS features (79-82). Ninety percent of $\mathrm{K}_{\mathrm{ATP}}-\mathrm{NDM}$ patients could switch from insulin therapy to sulfonylurea successfully $(79,83)$, with mutation severity $(77,84,85)$ and diabetes duration before the transition (86) predicting the likelihood of success. For patients who cannot completely transfer to sulfonylurea, combining insulin and sulfonylurea has shown favorable results (87).

6q24-TNDM. Although patients with 6q24-TNDM always present with growth retardation and hyperglycemia during the neonatal period, different etiologies, including paternal uniparental disomy, partial duplication of paternal origin, or a methylation defect of maternal origin on $6 \mathrm{q} 24$, all lead to the overexpression of PLAG1 and HYMAI, encoding a zinc finger protein (ZFP) and long noncoding RNA, respectively. In other cases, ZFP57 variants cause hypomethylation of multiple imprinted loci, including at the $6 q 24$ locus. The treatment for the first onset of diabetes is insulin, and many are treated with insulin during remission, while some are successfully treated with sulfonylureas or a combination of 
sulfonylureas and insulin $(88,89)$. Compared with $\mathrm{K}_{\text {ATP }}-\mathrm{TNDM}$ patients, patients with 6q24-TNDM were observed to have lower birthweight and earlier presentation (90). Some patients with 6q24-TNDM may also experience hyperinsulinemic hypoglycemia following diabetes remission (91). Certain congenital abnormalities, such as macroglossia, are characteristic of 6q24-TNDM and thus could help to distinguish this type of TNDM from other types in considering testing strategies.

\section{Syndromic diabetes}

In addition to RCAD syndrome due to $H N F 1 B$ variants as described above, other monogenic syndromes include DM as one of the clinical features. We describe the best-characterized of these syndromes below.

Wolfram syndrome. Two types of Wolfram syndrome (WS) corresponding to two causative genes have been identified to date. Wolfram syndrome 1 (WS1), characterized by diabetes insipidus, $\mathrm{DM}$, optic atrophy, and deafness, is a rare autosomal recessive disease caused by variants in wolframin ER transmembrane glycoprotein (WFS1). Severe cases with dominant heterozygous variants are also reported (92). Often, patients' first manifestation is DM at an average age of 6 years. Though most WS1 patients require daily insulin as therapy, the high morbidity and mortality rates as well as low average age of death make an accurate and timely diagnosis essential. Recently, a presentation similar to WS1 in many WFS1 mutation-negative patients was linked to variants in CDGSH iron sulfur domain 2 (CISD2) and thus named Wolfram syndrome 2 (WS2). Clinical features of WS2 resemble those of WS1 but without diabetes insipidus and with the addition of peptic ulcer bleeding and defective platelet aggregation (93). In addition, there are some WFS1 mutations that cause isolated diabetes with significantly reduced penetrance or nonpenetrance for other WS-related features $(94,95)$.

Insulin resistance due to insulin receptor defects. Genetic defects in the insulin receptor gene (INSR) result in several insulin resistance syndromes, which are distinguished from typical insulin resistance not only by their severity but by normal lipid profiles because the etiology is directly due to defects in insulin receptor signaling rather than obesity and its sequelae (96). The most common type is type A insulin resistance syndrome, which has autosomal dominant and autosomal recessive forms. Type A insulin resistance syndrome affects predominantly nonobese females and presents with extreme insulin resistance, acanthosis nigricans, hirsutism, and polycystic ovarian disease $(97,98)$. Rabson-Mendenhall syndrome (RMS) is an intermediate form of insulin resistance with autosomal recessive inheritance. Patients with RMS have clinical features of extreme insulin resistance, acanthosis nigricans, hirsutism, dental precocity, thick nails, pineal hyperplasia, genital enlargement in both males and females, abdominal distension, and other distinctive dysmorphic features $(99,100)$. The most severe form is Donohue syndrome (DS), an autosomal recessive disorder in which patients present with failure to thrive, severe hyperinsulinemia, and fasting hypoglycemia. Patients with DS seldom survive infancy (101). LOF variants in the fibronectin type III (FnIII) domain are proposed to be associated with more severe DS, and there are genotype-phenotype and structurephenotype correlations of INSR variants (102).
Lipodystrophy. Monogenic lipodystrophy is a group of diseases featuring a complete or partial lack of adipose tissue and adipose tissue-derived hormones, which results in insulin resistance and other metabolic complications. Unlike insulin receptor defects, the lack of adipose tissue in lipodystrophy leads to dyslipidemia and insulin resistance due to spillover of fat into ectopic areas, paradoxically similar to the consequences of obesity (96). Based on the loss of adipose tissue, this disease can be divided into congenital generalized lipodystrophy (CGL) and familial partial lipodystrophy (FPLD). CGL is an autosomal recessive disease; pathogenic variants in genes encoding 1-acylglycerol-3-phosphate $O$-acyltransferase 2 (AGPAT2) and Berardinelli-Seip congenital lipodystrophy 2 (BSCL2) account for most CGL cases, with rare cases being caused by pathogenic variants in CAV1 and PTRF. CGL patients show common features, such as generalized lipodystrophy, muscular appearance, DM, and dyslipidemia; however, patients with pathogenic BSCL2 variants display lower serum leptin levels than patients with pathogenic AGPAT2 variants (103) but a higher rate of developing intellectual disability (104). The majority of FPLD cases are caused by pathogenic variants in lamin A/C (LMNA) or PPAR $\gamma(P P A R G)$, and there are also other rarer forms caused by pathogenic variants in PLIN1, AKT2, LIPE, CIDEC, and PCYT1A. Body fat deficiency in FPLD is found on limbs, buttocks, and hips. Patients with pathogenic variants of either LMNA or PPARG appear to benefit similarly from leptin replacement therapy with metreleptin (105) in terms of improved glycemia and cardiometabolic outcomes.

Mitochondrial diabetes. Mitochondrial diabetes, also known as maternally inherited diabetes and deafness (MIDD), is caused by pathogenic variants in mitochondrial DNA, mostly tRNA variant m.3243A $>$ G. Patients often present with diabetes in adulthood, but a greater proportion of mutated mitochondrial genomes in the affected tissues is associated with a younger age of diagnosis of diabetes in some studies (106). The hearing loss associated with $\mathrm{m} .3243 \mathrm{~A}>\mathrm{G}$ is bilateral, sensorineural, and progressive, typically preceding the diagnosis of diabetes $(107,108)$. Other clinical features such as macular pattern dystrophy, nephropathy, and neurological symptoms are more common in rarer forms of mitochondrial diabetes than the classical form (109). The penetrance of mitochondrial diabetes is estimated to be nearly $100 \%$ by the age of 70 years. The disease etiology determined that patients have impaired insulin secretion, and insulin treatment is eventually required for most patients. The effects of other treatments, such as coenzyme $\mathrm{Q}_{10}$ and PPAR $\gamma$ agonists, were only evaluated in single cases, thus requiring caution for application. To better screen patients suspected to have mitochondrial diabetes, clinical features including diabetes and hearing loss on the maternal side are key. Tian et al. established a mitochondrial diabetes score system with good performance (100\% sensitivity, 69.9\% specificity) to select patients diagnosed with $\mathrm{T} 2 \mathrm{D}$ for genetic testing in a Chinese cohort (110), although this system needs validation in other populations.

\section{Challenges in identifying and diagnosing monogenic diabetes}

The broad application of personalized medicine to patients with monogenic diabetes faces challenges in two aspects: detecting patients suspected of having monogenic diabetes to pursue 


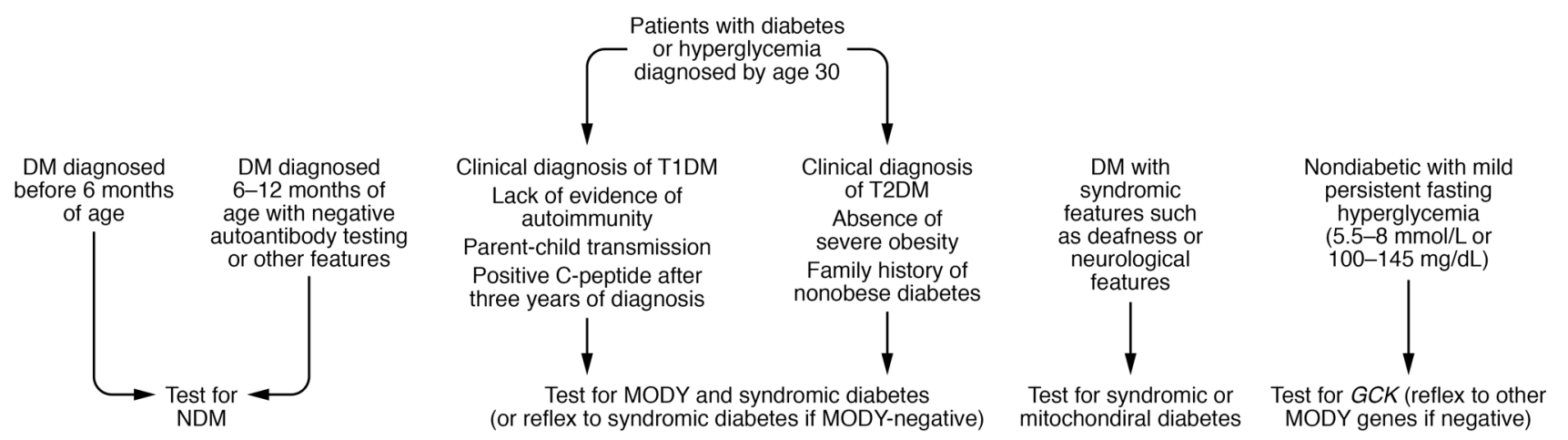

Figure 2. Proposed diagnostic algorithm for monogenic diabetes. Though the majority of patients diagnosed between 6 and 12 months have T1D, NDM can exist in these patients; genetic testing should be considered if they test negative for autoantibody, have extrapancreatic features, or have unusual family history $(1,2)$. High prevalence of MODY was observed in C-peptide-positive T2D diagnosed before 30 years regardless of metabolic syndrome status (116).

etiology-based therapies and accurately interpreting sequence variants of monogenic diabetes genes.

\section{Monogenic diabetes detection methods}

At present, practical guidelines for systematic screening for monogenic diabetes have been limited. The International Society for Pediatric and Adolescent Diabetes (ISPAD) has recommended testing for NDM in all patients diagnosed with diabetes before the age of 6 months as well as in patients diagnosed with diabetes before the age of 12 months with negative islet antibodies. This recommendation not only has the potential to dramatically improve care at the individual level when $\mathrm{K}_{\mathrm{ATP}}$-diabetes is diagnosed but has been shown to be cost-effective in this population (111). However, adult and pediatric T1D and T2D populations, which also include misdiagnosed patients with monogenic diabetes (112), are more challenging to screen routinely for MODY (111) and can be challenging especially for clinicians with limited experience diagnosing MODY. More complex screening criteria based on age of onset, family history, endogenous insulin secretion, nonobesity, and absence of pancreatic autoantibodies are needed to achieve cost-effectiveness and an ideal balance of sensitivity and specificity (113-115). The American Diabetes Association (ADA) recommends some scenarios for considering testing individuals who do not fit into the T1D or T2D classifications (2). A proposed algorithm to increase sensitivity is shown in Figure 2. Clinicians are referred to the primary source (116) as well as current ADA (2) and ISPAD guidelines (1) for further guidance; additional development is needed and is ongoing in this area.

Biomarkers or derived scores avoid reliance on clinical judgments and arbitrary cutoffs and establish a quantitative evaluation that could be validated and replicated across cohorts. The Swedish Better Diabetes Diagnosis (BDD) study showed that absence of glutamic acid decarboxylase (GAD), islet antigen-2, zinc transporter 8 antibodies, and insulin autoantibodies could be a good discriminator, since in this study, MODY patients were only identified from the antibody-negative group, and $15 \%$ of antibody-negative patients had MODY (115). However, other studies have shown that $1 \%-2 \%$ of patients diagnosed with MODY are GAD antibody positive (117), reducing the antibody's sensitivity as a screen. Meanwhile, the types of autoantibodies tested on each patient may vary depending on the clinic; thus, using negative antibodies as a screening method may not be practical without standardization. Table 3 summarizes published biomarkers other than pancreatic antibodies that have been utilized to distinguish monogenic diabetes subtypes from T1D or T2D. Limited by the low prevalence of monogenic diabetes, these biomarkers were developed in selected populations to differentiate the most common types of MODY.

In addition to biomarkers, Shields et al. established a MODY calculator predicting the possibility of testing positive for MODY given a set of common clinical criteria (118). In the initial cohort of White European patients who were diagnosed before the age of 35 , the cutoff of probability at $40 \%$ yields sensitivity of $96 \%$ and specificity of 91\% in differentiating MODY from T2D, and yields $87 \%$ sensitivity and $88 \%$ specificity for MODY versus T1D. Validations in other cohorts with different ethnic backgrounds show variable outcomes, suggesting room for improvement, including the need for a more ethnically diverse reference database.

\section{Selection of method and genes for testing}

Previously, molecular diagnosis of monogenic diabetes was usually performed through Sanger sequencing of one or several common-cause genes based on clinical suspicion. With the development of NGS, all known monogenic diabetes genes or even a patient's whole exome can be analyzed simultaneously. Targeted panels typically include all the MODY genes, or at least the most common ones, as well as the NDM and syndromic forms of diabetes genes. There are both advantages and disadvantages to using NGS gene panels. The low price of massively parallel sequencing enables the analysis of additional genes that were reported to be associated with syndromic forms of diabetes. This is useful because patients with syndromic forms of diabetes may lack or appear to lack the clinical features that would lead to testing of a single syndromic gene (119). However, it is important that diagnostic panels not include genes with weak or disputed associations with monogenic diabetes, or, if they are included for surveillance purposes, that they not be reported (120). The yields of these panels will not only facilitate molecular diagnosis but also add rare or novel variants to the knowledge base for future studies. Sanger confirmation is sometimes needed after variant discovery in NGS 
Table 3. Biomarkers for monogenic diabetes detection

\begin{tabular}{|c|c|c|c|c|c|}
\hline & Cutoff value & Differentiation & Sensitivity & Specificity & Reference \\
\hline \multicolumn{6}{|l|}{ Standard biomarkers } \\
\hline Fasting C-peptide & $\geq 0.62 \mathrm{ng} / \mathrm{mL}$ & MODY vs. T1D in children and adolescents & $93 \%$ & $90 \%$ & 194 \\
\hline $\begin{array}{l}\text { Random or glucagon-stimulated } \\
\text { C-peptide }\end{array}$ & $\geq 0.2 \mathrm{nmol} / \mathrm{L}$ & HNF1A- and HNF4A-MODY vs. T1D in adults & $100 \%$ & $96 \%$ & 116 \\
\hline \multirow[t]{5}{*}{ Autoantibodies } & GADA < 99th percentile & HNF1A-, HNF4A-, and GCK-MODY vs. T1D & $99 \%$ & $62 \%$ & 117 \\
\hline & IA-2 < 99th percentile & HNF1A-, HNF4A-, and GCK-MODY vs. T1D & $100 \%$ & $57 \%$ & 117 \\
\hline & GADA and $I A-2<99$ th percentile & HNF1A-, HNF4A-, and GCK-MODY vs. T1D & $99 \%$ & $82 \%$ & 117 \\
\hline & $\begin{array}{l}\text { GADA and/or IA-2 and/or } \\
\text { ZnT8A < 99th percentile }\end{array}$ & $\begin{array}{c}\text { HNF1A-, HNF4A-, and GCK-MODY vs. } \\
\text { not-known MODY in children }\end{array}$ & $100 \%$ & $88 \%$ & 115 \\
\hline & $\begin{array}{l}\text { GADA and/or IA-2 and/or ZnT8A } \\
\text { and/or IAA < 99th percentile }\end{array}$ & $\begin{array}{l}\text { HNF1A-, HNF4A-, and GCK-MODY vs. } \\
\text { not-known MODY in children }\end{array}$ & $100 \%$ & $89 \%$ & 115 \\
\hline \multicolumn{6}{|l|}{ Proposed biomarkers } \\
\hline \multirow[t]{2}{*}{ Serum 1,5-anhydroglucitol } & $>11 \mu \mathrm{g} / \mathrm{mL}$ & GCK-MODY vs. T2D & $75 \%$ & $75 \%$ & 195 \\
\hline & $>7.5 \mu \mathrm{g} / \mathrm{mL}$ & GCK-MODY vs. HNF1A-MODY & $86 \%$ & $84 \%$ & 195 \\
\hline \multirow{8}{*}{$\begin{array}{l}\text { Highly sensitive C-reactive proteins } \\
\text { (standard in UK) }\end{array}$} & $\leq 0.5 \mathrm{mg} / \mathrm{L}$ & HNF1A-MODY vs. T2D & $>74 \%$ & $>68 \%$ & 196 \\
\hline & $\leq 0.75 \mathrm{mg} / \mathrm{L}$ & HNF1A-MODY vs. T2D & $79 \%$ & $71 \%$ & 197 \\
\hline & $\leq 0.75 \mathrm{mg} / \mathrm{L}$ & HNF1A-MODY vs. T1D & $79 \%$ & $67 \%$ & 197 \\
\hline & $\leq 0.4 \mathrm{mg} / \mathrm{L}$ & HNF1A-MODY vs. T2D & $71 \%$ & $77 \%$ & 198 \\
\hline & $\leq 0.28 \mathrm{mg} / \mathrm{L}$ & GCK-MODY vs. T1D & $67 \%$ & $68 \%$ & 199 \\
\hline & $\leq 0.2 \mathrm{mg} / \mathrm{L}$ & HNF1A-MODY vs. T1D & $80 \%$ & $80 \%$ & 199 \\
\hline & $\leq 0.185 \mathrm{mg} / \mathrm{L}$ & HNF1A-MODY vs. GCK-MODY & $80 \%$ & $75 \%$ & 199 \\
\hline & $\leq 0.81 \mathrm{mg} / \mathrm{L}$ & $\begin{array}{l}\text { HNF1A-MODY vs. non-HNF1A-MODY } \\
\text { young-adult-onset nonautoimmune diabetes }\end{array}$ & $88 \%$ & $69 \%$ & 200 \\
\hline \multirow[t]{3}{*}{ Urinary C-peptide/creatinine ratio } & $\geq 0.2 \mathrm{nmol} / \mathrm{mmol}$ & HNF1A/4A-MODY vs. T1D & $97 \%$ & $96 \%$ & 201 \\
\hline & $\leq 3.1 \mathrm{nmol} / \mathrm{mmol}$ & HNF1A/4A MODY vs. T2D & $81 \%$ & $44 \%$ & 201 \\
\hline & $\geq 0.22 \mathrm{nmol} / \mathrm{mmol}$ & MODY vs. T1D in children and adolescents & $96 \%$ & $86 \%$ & 194 \\
\hline HDL-cholesterol & $\leq 1.56 \mathrm{mM}$ & GCK-MODY vs. T1D and HNF1A-MODY & $86 \%$ & $55 \%$ & 202 \\
\hline Plasma glycan GP30 & $<0.7 \%$ & $\begin{array}{l}\text { HNF1A-MODY vs. non-HNF1A-MODY } \\
\text { young-adult-onset nonautoimmune diabetes }\end{array}$ & $88 \%$ & $80 \%$ & 200 \\
\hline
\end{tabular}

panels, though increasingly less so except in difficult regions of the genome. Regardless of methodology, it is becoming increasingly clear that evaluating only exonic regions will overlook some causal variants, as variants in the noncoding regulatory and deep intronic regions and $5^{\prime}$ - and $3^{\prime}$-UTRs have also been implicated in monogenic diabetes $(16,121)$.

Searching for monogenic diabetes using exome or genome sequencing enables novel gene discovery and also requires caution. The coverage of exome sequencing may not be complete, leading to the risk of false negatives $(122,123)$. In addition, as exome or genome sequencing could discover variants that are potentially important to health or reproduction but are unrelated to the clinical indication, the reporting of such secondary findings must be addressed, with consideration of the recommendations of organizations such as the American College of Medical Genetics and Genomics (ACMG; ref. 124). With these caveats, this approach can serve as a powerful tool for searching for candidate genes in patients with monogenic diabetes for whom variants in known genes have not been found (125).

\section{Variant classification}

Key to diagnosing monogenic diabetes and other genetic conditions is not only identifying the variant but also distinguishing disease-causing variants from normal variation. Previous approaches to determine whether a variant identified in a patient was disease-causing involved sequencing a group of matched controls (usually 100-200 people) to assess the variant's presence in the general population. This approach was limited because the sample size was too small to rule out population prevalence being too high for the disease; e.g., HNF1A-diabetes has an estimated population prevalence of 1 in 10,000. Moreover, the extent to which rare but benign genetic variation existed in the population studied was not known and was thus probably underestimated. As NGS has begun to boom, the problem of large quantities of genetic data for interpretation has arisen for genetic diseases in general. The genetic and phenotypic heterogeneity of monogenic diabetes, and its overlapping features with T1D and T2D, together increase the difficulty of interpreting the pathogenicity of variants found in patients suspected to have monogenic diabetes. On the other hand, NGS emergence has led to the availability of exome and genome sequences of over 100,000 individuals of diverse ancestries in the gnomAD database, dramatically improving the ability to assess variant frequency in the general population. Additional resources have emerged, including computational predictive tools (126-128), and other sources of data, including phenotype specificity, famil- 
ial segregation, and functional studies, are also used. However, there is subjectivity in assigning pathogenicity to variants, and in the early 2010s, a lack of consistency of variant interpretation across laboratories became apparent.

In 2015, the ACMG and the Association for Molecular Pathology (AMP) jointly published a consensus recommendation on standards and guidelines for clinical genomic variant interpretation (129). The guidelines were developed through data sharing by a large number of American Board of Medical Genetics and Genomics-certified clinical molecular geneticists and pathologists from Clinical Laboratory Improvement Amendment/College of American Pathologists-accredited laboratories. The recommendations suggested that variants could be assigned to a five-tier system of classification: (a) pathogenic, (b) likely pathogenic, (c) uncertain significance, (d) likely benign, or (e) benign. The proposed sets of criteria include population data, computational and predictive data, clinical data, functional data (in vitro studies), and pedigree segregation. Each criterion is weighted by different levels of strength based on observed evidence and combined with other collected criteria to reach a conclusion. Since the publication of the initial ACMG/AMP guidelines, additional refinements have been published to improve rigor, including recommendations for evaluating the strength of evidence for LOF (130), standards for assessing functional studies (131), and application of a Bayesian quantitative point system (132).

\section{Value of establishing gene-specific rules}

The aim of the ACMG/AMP guidelines is to provide a universal set of criteria for interpreting variants for Mendelian disease. Additionally, each gene-disease pair requires further specification to reflect the specific disease frequency, clinical features, and genotype-phenotype relationships. In 2013, the Clinical Genome (ClinGen) Resource was founded by the National Human Genome Research Institute to serve as a knowledge base that defines gene-disease relationships, curate variants of genetic disease using a standardized approach, and distribute information about the variants to researchers and clinicians. Since then, dozens of expert panels and working groups have been formed to examine specific gene or disease groups for determining clinical significance and constructing gene-specific standardizations. The Monogenic Diabetes Expert Panel (MDEP), established in 2017, brings together experts and data to adapt the ACMG/AMP variant interpretation guidelines for monogenic diabetes genes and classify variants using these gene-specific rules, thereby improving the accuracy of variant classification in these genes and in turn improving the ability to accurately diagnose monogenic diabetes (133).

\section{Value of data sharing}

The establishing of guidelines is fundamental to standardized and concordant interpretation of monogenic diabetes gene variants. This process calls for expertise in endocrinology, molecular genetic testing, genetic counseling, and biochemistry. To reach the full potential of precision medicine in monogenic diabetes, centralization of case-level data is important. For instance, when the variant being evaluated is not observed in the general population but is observed in affected individuals, a higher number of occurrences leads to a higher level of evidence supporting pathogenicity. However, the uncommonness of monogenic diabetes often makes it difficult for individual laboratories to acquire enough cases. By pooling case data, expert panels can achieve levels of case-based evidence for pathogenicity not possible for any single laboratory or clinic.

\section{Value of functional evidence}

Well-established functional studies on variants boost the understanding of disease mechanisms and provide evidence supporting or disputing the pathogenicity of the variants. Studies have shown that functional analyses clarify variant interpretation in HNF1A-MODY variants, especially when family segregation data or phenotype data are not available (134). Caution is needed in using these data, because not all functional assays reflect the disease mechanism and not all variants impact the function in the same way. Full inspection of the consequences of a variant may require multiple assays to reach a conclusion (135). Systematic validation and statistical quantification of the level of strength of pathogenicity or benignity in functional assays are recommended (131). This approach encourages high-throughput mutation screenings, such as saturation mutagenesis (136) and systematic functional profiling of variants identified in the population (137, 138), which consist of pathogenic and benign variants. The MDEP is currently developing standards for evaluating evidence from luciferase assays for transactivation, which assess transcriptional activity of $H N F 1 A$ and $H N F 4 A$ variants, along with assays of DNA binding activity and protein expression $(138,139)$. For GCK variants, similar work is focused on the relative activity index of glucokinase as a measure of enzyme kinetic characteristics (140). In the longer term, multiplexed assays of variant effect (MAVEs) could provide comprehensive catalogs of allelic effects that can be interrogated to aid variant interpretation. This approach is particularly well suited for transcription factors such as HNF1A. It is important to note that functional evidence does not singlehandedly implicate a variant in disease; the functional data must be evaluated in concert with the population and clinical data to make a pathogenicity determination.

\section{Conclusion}

Accurate genetic diagnosis of monogenic diabetes is crucial for patients, since it helps optimize treatment, especially for some patients switching from insulin or metformin to low-dose sulfonylureas (HNF1A-MODY and HNF4A-MODY) or no treatment (GCK-MODY) or from insulin to high-dose sulfonylureas $\left(\mathrm{K}_{\mathrm{ATP}^{-}}\right.$ diabetes). Additionally, accurate monogenic diabetes diagnosis leads to better familial risk management and clinical course prediction. Advancement in genetic testing technology has increased the capacity of genetic diagnosis while decreasing sequencing cost. However, until we can offer genetic testing to every patient with diabetes, prioritizing patients with high suspicion of monogenic diabetes through assessment of their biomarker profiles or probability score is more practical. Monogenic diabetes provides an example of translating research findings into clinical practice that improves diagnosis and quality of life. Multidisciplinary expert collaboration and case sharing combined with incorporation of basic science into sequence variant 
interpretation will lead to improved diagnosis. Establishing clear guidelines for evaluating the causality of individual variants by this process is essential for widespread diagnosis of monogenic diabetes; more broadly, routine incorporation of emerging genomic data into the care of diabetes and disease in general is needed to realize the full potential of personalized and precision medicine. And as we celebrate the 100th anniversary of insulin's discovery, it seems fitting to now celebrate and disseminate our more recently discovered ability to identify individuals who can make their own insulin once they have received the appropriate genomic diagnosis and treatment.

\section{Acknowledgments}

This work was supported by NIH grants U24-HD093486 and U01-HG007775 (to TIP). ALG is a Wellcome Senior Fellow in Basic Biomedical Science and is supported by the Wellcome Trust (095101, 200837) and the NIH (U01-DK105535, U01DK085545, P30-DK116074).

Address correspondence to: Toni I. Pollin, University of Maryland School of Medicine, Department of Medicine, 670 West Baltimore Street, Room 4040, Baltimore, Maryland 21201, USA. Email: tpollin@som.umaryland.edu.
1. Hattersley AT, et al. ISPAD clinical practice consensus guidelines 2018: the diagnosis and management of monogenic diabetes in children and adolescents. Pediatr Diabetes.

2018;19(suppl 27):47-63.

2. American Diabetes Association. 2. Classification and diagnosis of diabetes: Standards of Medical Care in Diabetes-2020. Diabetes Care. 2020;43(suppl 1):S14-S31.

3. Tattersall RB. Mild familial diabetes with dominant inheritance. QJMed.1974;43(170):339-357.

4. Fajans SS, et al. The Banting Memorial Lecture 1978. Clinical and etiologic heterogeneity of idiopathic diabetes mellitus. Diabetes. 1978;27(11):1112-1125.

5. Weiss RE, Refetoff S, eds. Genetic Diagnosis of Endocrine Disorders. Academic Press; 2016.

6. Laver TW, et al. The common p.R114W HNF4A mutation causes a distinct clinical subtype of monogenic diabetes. Diabetes. 2016;65(10):3212-3217.

7. Sigma Type 2 Diabetes Consortium, et al. Association of a low-frequency variant in HNF1A with type 2 diabetes in a Latino population. JAMA. 2014;311(22):2305-2314.

8. Lango Allen $\mathrm{H}$, et al. Polygenic risk variants for type 2 diabetes susceptibility modify age at diagnosis in monogenic HNF1A diabetes. Diabetes. 2010;59(1):266-271.

9. Kleinberger JW, et al. Monogenic diabetes in overweight and obese youth diagnosed with type 2 diabetes: the TODAY clinical trial. Genet Med. 2018;20(6):583-590.

10. Laver $\mathrm{T}$, et al. Redefining the pathogenicity of Maturity Onset Diabetes of the Young (MODY) genes: BLK, PAX4 and KLF11 do not cause MODY. Paper presented at: Diabetes UK Professional Conference 2018; March 14-16, 2018; London ExCeL, London, UK. https://doi. org/10.1111/dme.2_13570. Accessed Jan 8, 2020.

11. Patel KA, et al. Heterozygous RFX6 protein truncating variants are associated with MODY with reduced penetrance. Nat Commun. 2017;8(1):888.

12. Thanabalasingham G, Owen KR. Diagnosis and management of maturity onset diabetes of the young (MODY). BMJ. 2011;343:d6044.

13. Murphy R, et al. Clinical implications of a molecular genetic classification of monogenic betacell diabetes. Nat Clin Pract Endocrinol Metab. 2008;4(4):200-213.

14. Steele AM, et al. Prevalence of vascular complications among patients with glucokinase mutations and prolonged, mild hyperglycemia. JAMA. 2014;311(3):279-286.

15. Haliyur R, et al. Human islets expressing HNF1A variant have defective $\beta$ cell transcriptional regulatory networks. J Clin Invest. 2019;129(1):246-251.

16. Colclough K, et al. Mutations in the genes encoding the transcription factors hepatocyte nuclear factor $1 \alpha$ and $4 \alpha$ in maturity-onset diabetes of the young and hyperinsulinemic hypoglycemia. Hum Mutat. 2013;34(5):669-685.

17. Pearson ER, et al. Macrosomia and hyperinsulinaemic hypoglycaemia in patients with heterozygous mutations in the HNF4A gene. PLoS Med. 2007;4(4):e118.

18. Yau D, et al. Congenital hyperinsulinism due to mutations in HNF1A. Eur JMed Genet. 2020;63(6):103928.

19. Shepherd M, et al. A genetic diagnosis of HNF1A diabetes alters treatment and improves glycaemic control in the majority of insulin-treated patients. Diabet Med.2009;26(4):437-441.

20. Pearson ER, et al. Sensitivity to sulphonylureas in patients with hepatocyte nuclear factor-1alpha gene mutations: evidence for pharmacogenetics in diabetes. Diabet Med. 2000;17(7):543-545.

21. Pearson ER, et al. Genetic cause of hyperglycaemia and response to treatment in diabetes. Lancet. 2003;362(9392):1275-1281.

22. Fantasia KL, Steenkamp DW. Optimal glycemic control in a patient with HNF1A MODY with GLP-1 RA monotherapy: implications for future therapy. JEndocr Soc. 2019;3(12):2286-2289.

23. Christensen AS, et al. Efficacy and safety of glimepiride with or without linagliptin treatment in patients with HNF1A diabetes (maturityonset diabetes of the young type 3): a randomized, double-blinded, placebo-controlled, crossover trial (GLIMLINA). Diabetes Care. 2020;43(9):2025-2033

24. Byrne MM, et al. Insulin secretory abnormalities in subjects with hyperglycemia due to glucokinase mutations. J Clin Invest. 1994;93(3):1120-1130.

25. Osbak KK, et al. Update on mutations in glucokinase (GCK), which cause maturity-onset diabetes of the young, permanent neonatal diabetes, and hyperinsulinemic hypoglycemia. Hum Mutat. 2009;30(11):1512-1526.

26. Chakera AJ, et al. The $0.1 \%$ of the population with glucokinase monogenic diabetes can be recognized by clinical characteristics in pregnancy: the Atlantic Diabetes in Pregnancy cohort. Diabetes Care. 2014;37(5):1230-1236.

27. Carmody D, et al. GCK-MODY in the US National
Monogenic Diabetes Registry: frequently misdiagnosed and unnecessarily treated. Acta Diabetol. 2016;53(5):703-708.

28. Stride A, et al. Cross-sectional and longitudinal studies suggest pharmacological treatment used in patients with glucokinase mutations does not alter glycaemia. Diabetologia. 2014;57(1):54-56.

29. Wedrychowicz A, et al. Phenotype heterogeneity in glucokinase-maturity-onset diabetes of the young (GCK-MODY) patients. J Clin Res Pediatr Endocrinol. 2017;9(3):246-252.

30. Cuesta-Munoz AL, et al. Clinical heterogeneity in monogenic diabetes caused by mutations in the glucokinase gene (GCK-MODY). Diabetes Care. 2010;33(2):290-292.

31. Szopa M, et al. Prevalence of retinopathy in adult patients with GCK-MODY and HNF1A-MODY. Exp Clin Endocrinol Diabetes. 2015;123(9):524-528.

32. Hattersley AT, et al. Mutations in the glucokinase gene of the fetus result in reduced birth weight. Nat Genet. 1998;19(3):268-270.

33. Caswell RC, et al. Noninvasive fetal genotyping by droplet digital PCR to identify maternally inherited monogenic diabetes variants. Clin Chem. 2020;66(7):958-965.

34. Edghill EL, et al. HNF1B deletions in patients with young-onset diabetes but no known renal disease. Diabet Med. 2013;30(1):114-117.

35. Dubois-Laforgue D, et al. Intellectual disability in patients with MODY due to hepatocyte nuclear factor 1B (HNF1B) molecular defects. Diabetes Metab. 2017;43(1):89-92.

36. Dubois-Laforgue D, et al. Diabetes, associated clinical spectrum, long-term prognosis, and genotype/phenotype correlations in 201 adult patients with hepatocyte nuclear factor 1B (HNF1B) molecular defects. Diabetes Care. 2017;40(11):1436-1443.

37. Clissold RL, et al. Chromosome 17q12 microdeletions but not intragenic HNF1B mutations link developmental kidney disease and psychiatric disorder. Kidney Int. 2016;90(1):203-211.

38. Tomura $\mathrm{H}$, et al. Loss-of-function and dominant-negative mechanisms associated with hepatocyte nuclear factor-1beta mutations in familial type 2 diabetes mellitus. J Biol Chem. 1999;274(19):12975-12978.

39. Lindner TH, et al. A novel syndrome of diabetes mellitus, renal dysfunction and genital malformation associated with a partial deletion of the pseudo-POU domain of hepatocyte nuclear factor-1beta. Hum Mol Genet. 1999;8(11):2001-2008. 
40. Bowman P, et al. Heterozygous ABCC8 mutations are a cause of MODY. Diabetologia. 2012;55(1):123-127.

41. Bonnefond A, et al. Whole-exome sequencing and high throughput genotyping identified KCNJ11 as the thirteenth MODY gene. PLoS One. 2012;7(6):e37423.

42. Prudente $S$, et al. Loss-of-function mutations in APPL1 in familial diabetes mellitus. Am J Hum Genet. 2015;97(1):177-185.

43. Simaite D, et al. Recessive mutations in PCBD1 cause a new type of early-onset diabetes. Diabetes. 2014;63(10):3557-3564.

44. Polak M, Cave H. Neonatal diabetes mellitus: a disease linked to multiple mechanisms. Orphanet JRare Dis. 2007;2:12.

45. Aguilar-Bryan L, Bryan J. Neonatal diabetes mellitus. Endocr Rev. 2008;29(3):265-291.

46. Busiah K, et al. Neuropsychological dysfunction and developmental defects associated with genetic changes in infants with neonatal diabetes mellitus: a prospective cohort study [corrected]. Lancet Diabetes Endocrinol. 2013;1(3):199-207.

47. Iafusco D, et al. Minimal incidence of neonatal/ infancy onset diabetes in Italy is 1:90,000 live births. Acta Diabetol. 2012;49(5):405-408.

48. Slingerland AS, et al. Referral rates for diagnostic testing support an incidence of permanent neonatal diabetes in three European countries of at least 1 in 260,000 live births. Diabetologia. 2009;52(8):1683-1685.

49. Temple IK, Shield JP. 6q24 transient neonatal diabetes. Rev Endocr Metab Disord. 2010;11(3):199-204.

50. Gloyn AL, et al. Activating mutations in the gene encoding the ATP-sensitive potassium-channel subunit Kir6.2 and permanent neonatal diabetes. NEngl JMed. 2004;350(18):1838-1849.

51. Babenko AP, et al. Activating mutations in the ABCC8 gene in neonatal diabetes mellitus. N Engl J Med. 2006;355(5):456-466.

52. Gloyn AL, et al. Relapsing diabetes can result from moderately activating mutations in KCNJ11. Hum Mol Genet. 2005;14(7):925-934.

53. Garin I, et al. Recessive mutations in the INS gene result in neonatal diabetes through reduced insulin biosynthesis. Proc Natl Acad Sci U S A. 2010;107(7):3105-3110.

54. Bonnefond A, et al. Disruption of a novel Kruppel-like transcription factor p300regulated pathway for insulin biosynthesis revealed by studies of the c.-331 INS mutation found in neonatal diabetes mellitus. J Biol Chem. 2011;286(32):28414-28424.

55. Edghill EL, et al. Hepatocyte nuclear factor-1 $\beta$ mutations cause neonatal diabetes and intrauterine growth retardation: support for a critical role of HNF-1 $\beta$ in human pancreatic development. Diabet Med. 2006;23(12):1301-1306.

56. Yorifuji T, et al. Neonatal diabetes mellitus and neonatal polycystic, dysplastic kidneys: phenotypically discordant recurrence of a mutation in the hepatocyte nuclear factor- $1 \beta$ gene due to germline mosaicism. JClin Endocrinol Metab. 2004;89(6):2905-2908.

57. Kelsey MM, Zeitler PS. Insulin resistance of puberty. Curr Diab Rep. 2016;16(7):64.

58. Rubio-Cabezas O, et al. Permanent neonatal diabetes mellitus - the importance of diabetes differential diagnosis in neonates and infants. Eur J Clin Invest. 2011;41(3):323-333.

59. Johnson MB, et al. Monogenic autoimmune diseases of the endocrine system. Lancet Diabetes Endocrinol. 2016;4(10):862-872.

60. Johnson MB, et al. A type 1 diabetes genetic risk score can discriminate monogenic autoimmunity with diabetes from early-onset clustering of polygenic autoimmunity with diabetes. Diabetologia. 2018;61(4):862-869.

61. Bacchetta R, et al. From IPEX syndrome to FOXP3 mutation: a lesson on immune dysregulation. Ann N Y Acad Sci. 2018;1417(1):5-22.

62. Rubio-Cabezas O, et al. Wolcott-Rallison syndrome is the most common genetic cause of permanent neonatal diabetes in consanguineous families. J Clin Endocrinol Metab. 2009;94(11):4162-4170.

63. De Franco E, et al. The effect of early, comprehensive genomic testing on clinical care in neonatal diabetes: an international cohort study. Lancet. 2015;386(9997):957-963.

64. De Franco E, et al. YIPF5 mutations cause neonatal diabetes and microcephaly through endoplasmic reticulum stress. J Clin Invest. 2020;130(12):6338-6353.

65. Vaxillaire M, et al. Kir6.2 mutations are a common cause of permanent neonatal diabetes in a large cohort of French patients. Diabetes. 2004;53(10):2719-2722.

66. Flanagan SE, et al. Mutations in KCNJ11, which encodes Kir6.2, are a common cause of diabetes diagnosed in the first 6 months of life, with the phenotype determined by genotype. Diabetologia. 2006;49(6):1190-1197.

67. Pipatpolkai T, et al. New insights into $K_{\text {ATP }}$ channel gene mutations and neonatal diabetes mellitus. Nat Rev Endocrinol. 2020;16(7):378-393.

68. Ashcroft FM, et al. Neonatal diabetes and the $\mathrm{K}_{\text {ATP }}$ channel: from mutation to therapy. Trends Endocrinol Metab. 2017;28(5):377-387.

69. Patch AM, et al. Mutations in the ABCC8 gene encoding the SUR1 subunit of the KATP channel cause transient neonatal diabetes, permanent neonatal diabetes or permanent diabetes diagnosed outside the neonatal period. Diabetes Obes Metab. 2007;9(suppl 2):28-39.

70. Lang V, Light PE. The molecular mechanisms and pharmacotherapy of ATP-sensitive potassium channel gene mutations underlying neonatal diabetes. Pharmgenomics Pers Med. 2010;3:145-161.

71. Yorifuji T, et al. The C42R mutation in the Kir6.2 (KCNJ11) gene as a cause of transient neonatal diabetes, childhood diabetes, or later-onset, apparently type 2 diabetes mellitus. JClin Endocrinol Metab. 2005;90(6):3174-3178.

72. Aguilar-Bryan L, et al. Cloning of the beta cell high-affinity sulfonylurea receptor: a regulator of insulin secretion. Science. 1995;268(5209):423-426.

73. Thomas P, et al. Mutation of the pancreatic islet inward rectifier Kir6.2 also leads to familial persistent hyperinsulinemic hypoglycemia of infancy. Hum Mol Genet. 1996;5(11):1809-1812.

74. Glaser B, et al. Hyperinsulinism caused by paternal-specific inheritance of a recessive mutation in the sulfonylurea-receptor gene. Diabetes.
1999;48(8):1652-1657.

75. Slingerland AS, Hattersley AT. Mutations in the Kir6.2 subunit of the KATP channel and permanent neonatal diabetes: new insights and new treatment. Ann Med. 2005;37(3):186-195.

76. Flanagan SE, et al. Update of mutations in the genes encoding the pancreatic beta-cell K(ATP) channel subunits Kir6.2 (KCNJ11) and sulfonylurea receptor 1 (ABCC8) in diabetes mellitus and hyperinsulinism. Hum Mutat. 2009;30(2):170-180.

77. Proks P, et al. Molecular basis of Kir6.2 mutations associated with neonatal diabetes or neonatal diabetes plus neurological features. Proc Natl Acad Sci U S A. 2004;101(50):17539-17544.

78. Hattersley AT, Ashcroft FM. Activating mutations in Kir6.2 and neonatal diabetes: new clinical syndromes, new scientific insights, and new therapy. Diabetes. 2005;54(9):2503-2513.

79. Pearson ER, et al. Switching from insulin to oral sulfonylureas in patients with diabetes due to Kir6.2 mutations. $N$ Engl J Med. 2006;355(5):467-477.

80. Bowman P, et al. Effectiveness and safety of longterm treatment with sulfonylureas in patients with neonatal diabetes due to KCNJ11 mutations: an international cohort study. Lancet Diabetes Endocrinol. 2018;6(8):637-646.

81. Mlynarski W, et al. Sulfonylurea improves CNS function in a case of intermediate DEND syndrome caused by a mutation in KCNJ11. Nat Clin Pract Neurol. 2007;3(11):640-645.

82. Slingerland AS, et al. Sulphonylurea therapy improves cognition in a patient with the V59M KCNJ11 mutation. Diabet Med. 2008;25(3):277-281.

83. Rafiq M, et al. Effective treatment with oral sulfonylureas in patients with diabetes due to sulfonylurea receptor 1 (SUR1) mutations. Diabetes Care. 2008;31(2):204-209.

84. Masia R, et al. An ATP-binding mutation (G334D) in KCNJ11 is associated with a sulfonylurea-insensitive form of developmental delay, epilepsy, and neonatal diabetes. Diabetes. 2007;56(2):328-336.

85. Sumnik Z, et al. Sulphonylurea treatment does not improve psychomotor development in children with KCNJ11 mutations causing permanent neonatal diabetes mellitus accompanied by developmental delay and epilepsy (DEND syndrome). Diabet Med. 2007;24(10):1176-1178.

86. Babiker T, et al. Successful transfer to sulfonylureas in KCNJ11 neonatal diabetes is determined by the mutation and duration of diabetes. Diabetologia. 2016;59(6):1162-1166.

87. Misra S, et al. Permanent neonatal diabetes: combining sulfonylureas with insulin may be an effective treatment. Diabet Med.2018;30(2):170-180.

88. Fu JL, et al. Relapsed 6q24-related transient neonatal diabetes mellitus successfully treated with sulfonylurea. Chin Med J (Engl). 2019;132(7):846-848.

89. Carmody D, et al. Role of noninsulin therapies alone or in combination in chromosome 6q24related transient neonatal diabetes: sulfonylurea improves but does not always normalize insulin secretion. Diabetes Care. 2015;38(6):e86-87.

90. Docherty LE, et al. Clinical presentation of 6q24 transient neonatal diabetes mellitus (6q24 TNDM) and genotype-phenotype correlation in 
an international cohort of patients. Diabetologia. 2013;56(4):758-762.

91. Flanagan SE, et al. Hypoglycaemia following diabetes remission in patients with 6q24 methylation defects: expanding the clinical phenotype. Diabetologia. 2013;56(1):218-221.

92. De Franco E, et al. Dominant ER stress-inducing WFS1 mutations underlie a genetic syndrome of neonatal/infancy-onset diabetes, congenital sensorineural deafness, and congenital cataracts. Diabetes. 2017;66(7):2044-2053.

93. Rigoli L, Di Bella C. Wolfram syndrome 1 and Wolfram syndrome 2. Curr Opin Pediatr. 2012;24(4):512-517.

94. Bansal V, et al. Identification of a missense variant in the WFS1 gene that causes a mild form of Wolfram syndrome and is associated with risk for type 2 diabetes in Ashkenazi Jewish individuals. Diabetologia. 2018;61(10):2180-2188.

95. Bonnycastle LL, et al. Autosomal dominant diabetes arising from a Wolfram syndrome 1 mutation. Diabetes. 2013;62(11):3943-3950.

96. Semple RK, et al. Postreceptor insulin resistance contributes to human dyslipidemia and hepatic steatosis. J Clin Invest. 2009;119 (2):315-322.

97. O'Rahilly S, Moller DE. Mutant insulin receptors in syndromes of insulin resistance. Clin Endocrinol (Oxf). 1992;36(2):121-132.

98. Hegele RA. Monogenic forms of insulin resistance: apertures that expose the common metabolic syndrome. Trends Endocrinol Metab. 2003;14(8):371-377.

99. al-Gazali LI, et al. A syndrome of insulin resistance resembling leprechaunism in five sibs of consanguineous parents. J Med Genet. 1993;30(6):470-475.

100.Kadowaki H, et al. Four mutant alleles of the insulin receptor gene associated with genetic syndromes of extreme insulin resistance. Biochem Biophys Res Commun. 1997;237(3):516-520.

101. Kirkwood A, et al. Donohue syndrome: a review of literature, case series, and anesthetic considerations. Paediatr Anaesth. 2018;28(1):23-27.

102. Hosoe J, et al. Structural basis and genotype-phenotype correlations of INSR mutations causing severe insulin resistance. Diabetes. 2017;66(10):2713-2723.

103.Agarwal AK, et al. Phenotypic and genetic heterogeneity in congenital generalized lipodystrophy. JClin Endocrinol Metab. 2003;88(10):4840-4847.

104.Van Maldergem L, et al. Genotype-phenotype relationships in Berardinelli-Seip congenital lipodystrophy. J Med Genet. 2002;39(10):722-733.

105. Sekizkardes $\mathrm{H}$, et al. Efficacy of metreleptin treatment in familial partial lipodystrophy due to PPARG vs LMNA pathogenic variants. J Clin Endocrinol Metab. 2019;104(8):3068-3076.

106. Ohkubo K, et al. Mitochondrial gene mutations in the tRNA(Leu(UUR)) region and diabetes: prevalence and clinical phenotypes in Japan. Clin Chem. 2001;47(9):1641-1648.

107. Uimonen S, et al. Hearing impairment in patients with 3243A-->G mtDNA mutation: phenotype and rate of progression. Hum Genet. 2001;108(4):284-289.

108. Murphy R, et al. Clinical features, diagnosis and management of maternally inherited diabetes and deafness (MIDD) associated with the
$3243 \mathrm{~A}>\mathrm{G}$ mitochondrial point mutation. Diabet Med.2008;25(4):383-399.

109. Decoux-Poullot AG, et al. Clinical phenotype of mitochondrial diabetes due to rare mitochondrial DNA mutations. Ann Endocrinol (Paris). 2020;81(2-3):68-77.

110. Tian LH, et al. A screening approach for mitochondrial tRNA ${ }^{\text {Leu(UUR) }}$ A3243G mutation in a hospital-based population with diabetes. Chin Med J (Engl). 2018;131(9):1117-1119.

111. Naylor R. Economics of genetic testing for diabetes. Curr Diab Rep. 2019;19(5):23.

112. Todd J, et al. Monogenic diabetes in the progress for diabetes genetics in youth (ProDiGY) collaboration. Diabetes. 2018;18(8):57.

113. Naylor RN, et al. Cost-effectiveness of MODY genetic testing: translating genomic advances into practical health applications. Diabetes Care. 2014;37(1):202-209.

114. Thomas ER, et al. Diagnosis of monogenic diabetes: 10-year experience in a large multi-ethnic diabetes center. J Diabetes Investig. 2016;7(3):332-337.

115. Carlsson A, et al. Absence of islet autoantibodies and modestly raised glucose values at diabetes diagnosis should lead to testing for MODY: lessons from a 5 -year pediatric swedish national cohort study. Diabetes Care. 2020;43(1):82-89.

116. Thanabalasingham $\mathrm{G}$, et al. Systematic assessment of etiology in adults with a clinical diagnosis of young-onset type 2 diabetes is a successful strategy for identifying maturity-onset diabetes of the young. Diabetes Care. 2012;35(6):1206-1212.

117. McDonald TJ, et al. Islet autoantibodies can discriminate maturity-onset diabetes of the young (MODY) from Type 1 diabetes. Diabet Med. 2011;28(9):1028-1033.

118. Shields BM, et al. The development and validation of a clinical prediction model to determine the probability of MODY in patients with young-onset diabetes. Diabetologia. 2012;55(5):1265-1272.

119. Ellard S, et al. Improved genetic testing for monogenic diabetes using targeted next-generation sequencing. Diabetologia. 2013;56(9):1958-1963.

120. Ellard S, et al. Prediction algorithms: pitfalls in interpreting genetic variants of autosomal dominant monogenic diabetes. JClin Invest. 2020;130(1):14-16.

121. Carmody D, et al. Continued lessons from the INS gene: an intronic mutation causing diabetes through a novel mechanism. JMed Genet. 2015;52(9):612-616.

122. Kwak SH, et al. Clinical whole exome sequencing in early onset diabetes patients. Diabetes Res Clin Pract. 2016;122:71-77.

123. Johansson S, et al. Exome sequencing and genetic testing for MODY. PLoS One. 2012;7(5):e38050.

124. Kalia SS, et al. Recommendations for reporting of secondary findings in clinical exome and genome sequencing, 2016 update (ACMG SF v2.0): a policy statement of the American College of Medical Genetics and Genomics. Genet Med. 2017;19(2):249-255.

125. Shim YJ, et al. Identification of candidate gene variants in Korean MODY Families by whole-exome sequencing. Horm Res Paediatr. 2015;83(4):242-251.

126. Ng PC, Henikoff S. SIFT: predicting amino acid changes that affect protein function. Nucleic Acids Res. 2003;31(13):3812-3814

127. Adzhubei IA, et al. A method and server for predicting damaging missense mutations. Nat Methods. 2010;7(4):248-249.

128. Ioannidis NM, et al. REVEL: an ensemble method for predicting the pathogenicity of rare missense variants. Am J Hum Genet. 2016;99(4):877-885.

129. Richards S, et al. Standards and guidelines for the interpretation of sequence variants: a joint consensus recommendation of the American College of Medical Genetics and Genomics and the Association for Molecular Pathology. Genet Med. 2015;17(5):405-424.

130. Abou Tayoun AN, et al. Recommendations for interpreting the loss of function PVS1 ACMG/AMP variant criterion. Hum Mutat. 2018;39(11):1517-1524.

131. Brnich SE, et al. Recommendations for application of the functional evidence PS3/BS3 criterion using the ACMG/AMP sequence variant interpretation framework. Genome Med. 2019;12(1):3.

132. Tavtigian SV, et al. Fitting a naturally scaled point system to the ACMG/AMP variant classification guidelines [published online July 26, 2020]. Hum Mutat. https://doi.org/10.1002/humu.24088.

133. Rivera-Muñoz EA, et al. ClinGen Variant Curation Expert Panel experiences and standardized processes for disease and gene-level specification of the ACMG/AMP guidelines for sequence variant interpretation. Hum Mutat. 2018;39(11):1614-1622.

134. Malikova J, et al. Functional analyses of HNF1A-MODY variants refine the interpretation of identified sequence variants. JClin Endocrinol Metab. 2020;105(4):dgaa051.

135. Raimondo A, et al. Phenotypic severity of homozygous GCK mutations causing neonatal or childhood-onset diabetes is primarily mediated through effects on protein stability. Hum Mol Genet. 2014;23(24):6432-6440.

136. Majithia AR, et al. Prospective functional classification of all possible missense variants in PPARG. Nat Genet. 2016;48(12):1570-1575.

137. Thormaehlen AS, et al. Systematic cell-based phenotyping of missense alleles empowers rare variant association studies: a case for LDLR and myocardial infarction. PLoS Genet. 2015;11(2):e1004855.

138. Althari S, et al. Unsupervised clustering of missense variants in HNF1A using multidimensional functional data aids clinical interpretation. Am J Hum Genet. 2020;107(4):670-682.

139. Najmi LA, et al. Functional investigations of HNF1A identify rare variants as risk factors for type 2 diabetes in the general population. Diabetes. 2017;66(2):335-346.

140. Gloyn AL, et al. Glucokinase and the regulation of blood sugar. In: Matschinsky FM, Magnuson MA, eds. Glucokinase and Glycemic Disease: From Basics to Novel Therapeutics. Karger; 2004:92-109.

141. Stoffers DA, et al. Early-onset type-II diabetes mellitus (MODY4) linked to IPF1. Nat Genet. 1997;17(2):138-139.

142. Fajans SS, et al. Obesity and hyperinsulinemia in a family with pancreatic agenesis and MODY caused by the IPF1 mutation Pro63fsX60. Transl Res. 2010;156(1):7-14. 
143. Caetano LA, et al. PDX1 -MODY and dorsa pancreatic agenesis: new phenotype of a rare disease. Clin Genet. 2018;93(2):382-386.

144.Yu H, et al. Identification of a novel mutation site in maturity-onset diabetes of the young in a Chinese family by whole-exome sequencing. Mol Med Rep. 2019;20(3):2373-2380.

145. Horikawa Y, Enya M. Genetic dissection and clinical features of MODY6 (NEUROD1-MODY). Curr Diab Rep. 2019;19(3):12.

146. Raeder H, et al. Pancreatic lipomatosis is a structural marker in nondiabetic children with mutations in carboxyl-ester lipase. Diabetes. 2007;56(2):444-449.

147. Raeder H, et al. Mutations in the CEL VNTR cause a syndrome of diabetes and pancreatic exocrine dysfunction. Nat Genet. 2006;38(1):54-62.

148.Vesterhus M, et al. Pancreatic function in carboxyl-ester lipase knockout mice. Pancreatology. 2010;10(4):467-476.

149. Liu M, et al. INS-gene mutations: from genetics and beta cell biology to clinical disease. $\mathrm{Mol}$ Aspects Med. 2015;42:3-18.

150. Stoy J, et al. Insulin gene mutations as a cause of permanent neonatal diabetes. Proc Natl Acad Sci U S A. 2007;104(38):15040-15044.

151. Edghill EL, et al. Insulin mutation screening in 1,044 patients with diabetes: mutations in the INS gene are a common cause of neonatal diabetes but a rare cause of diabetes diagnosed in childhood or adulthood. Diabetes. 2008;57(4):1034-1042.

152. Molven A, et al. Mutations in the insulin gene can cause MODY and autoantibody-negative type 1 diabetes. Diabetes. 2008;57(4):1131-1135.

153. Gloyn AL, et al. Mutations in the genes encoding the pancreatic beta-cell KATP channel subunits Kir6.2 (KCNJ11) and SUR1 (ABCC8) in diabetes mellitus and hyperinsulinism. Hum Mutat. 2006;27(3):220-231.

154. De Franco E, et al. Update of variants identified in the pancreatic beta-cell KATP channel genes KCNJ11 and ABCC8 in individuals with congenital hyperinsulinism and diabetes. Hum Mutat. 2020;41(5):884-905.

155. Shaw-Smith C, et al. GATA4 mutations are a cause of neonatal and childhood-onset diabetes. Diabetes. 2014;63(8):2888-2894.

156. Allen HL, et al. GATA6 haploinsufficiency causes pancreatic agenesis in humans. Nat Genet. 2011;44(1):20-22.

157. De Franco E, et al. GATA6 mutations cause a broad phenotypic spectrum of diabetes from pancreatic agenesis to adult-onset diabetes without exocrine insufficiency. Diabetes. 2013;62(3):993-997.

158. Borowiec M, et al. Phenotype variability and neonatal diabetes in a large family with heterozygous mutation of the glucokinase gene. Acta Diabetol. 2011;48(3):203-208.

159. Bennett K, et al. Four novel cases of permanent neonatal diabetes mellitus caused by homozygous mutations in the glucokinase gene. Pediatr Diabetes. 2011;12(3 pt 1):192-196.

160.Esquiaveto-Aun AM, et al. A new compound heterozygosis for inactivating mutations in the glucokinase gene as cause of permanent neonatal diabetes mellitus (PNDM) in double-first cousins. Diabetol Metab Syndr. 2015;7:101.

161. Wen X, Yang Y. Emerging roles of GLIS3 in neonatal diabetes, type 1 and type 2 diabetes. JMol Endocrinol. 2017;58(2):R73-R85.

162.Alghamdi KA, et al. Extended clinical features associated with novel Glis3 mutation: a case report. BMC Endocr Disord. 2017;17(1):14.

163. Fu C, et al. Mutation screening of the GLIS3 gene in a cohort of 592 Chinese patients with congenital hypothyroidism. Clin Chim Acta. 2018;476:38-43.

164. Poulton CJ, et al. Microcephaly with simplified gyration, epilepsy, and infantile diabetes linked to inappropriate apoptosis of neural progenitors. Am J Hum Genet. 2011;89(2):265-276.

165. Polak M, et al. Heterozygous missense mutations in the insulin gene are linked to permanent diabetes appearing in the neonatal period or in early infancy: a report from the French ND (Neonatal Diabetes) Study Group. Diabetes. 2008;57(4):1115-1119.

166. Colombo C, et al. Seven mutations in the human insulin gene linked to permanent neonatal/ infancy-onset diabetes mellitus. J Clin Invest. 2008;118(6):2148-2156.

167. Bonfanti R, et al. Insulin gene mutations as cause of diabetes in children negative for five type 1 diabetes autoantibodies. Diabetes Care. 2009;32(1):123-125.

168. Rubio-Cabezas O, et al. Testing for monogenic diabetes among children and adolescents with antibody-negative clinically defined Type 1 diabetes. Diabet Med. 2009;26(10):1070-1074.

169.Porksen S, et al. Disease progression and search for monogenic diabetes among children with new onset type 1 diabetes negative for ICA GAD- and IA-2 antibodies. BMC Endocr Disord. 2010;10:16

170. Flanagan SE, et al. Analysis of transcription factors key for mouse pancreatic development establishes NKX2-2 and MNX1 mutations as causes of neonatal diabetes in man. Cell Metab. 2014;19(1):146-154.

171. Rubio-Cabezas O, et al. Permanent neonatal diabetes and enteric anendocrinosis associated with biallelic mutations in NEUROG3. Diabetes. 2011;60(4):1349-1353.

172. Pinney SE, et al. Neonatal diabetes and congenital malabsorptive diarrhea attributable to a novel mutation in the human neurogenin-3 gene coding sequence. J Clin Endocrinol Metab. 2011;96(7):1960-1965.

173. Wang J, et al. Mutant neurogenin-3 in congenital malabsorptive diarrhea. $N$ Engl J Med. 2006;355(3):270-280.

174. Yasuda T, et al. PAX6 mutation as a genetic factor common to aniridia and glucose intolerance. Diabetes. 2002;51(1):224-230.

175. Wen JH, et al. Paired box 6 (PAX6) regulates glucose metabolism via proinsulin processing mediated by prohormone convertase $1 / 3$ (PC1/3). Diabetologia. 2009;52(3):504-513.

176. Solomon BD, et al. Compound heterozygosity for mutations in PAX6 in a patient with complex brain anomaly, neonatal diabetes mellitus, and microophthalmia. Am JMed Genet $A$. 2009;149A(11):2543-2546.

177. Stoffers DA, et al. Pancreatic agenesis attrib- utable to a single nucleotide deletion in the human IPF1 gene coding sequence. Nat Genet. 1997;15(1):106-110.

178. Wright NM, et al. Permanent neonatal diabetes mellitus and pancreatic exocrine insufficiency resulting from congenital pancreatic agenesis. Am J Dis Child. 1993;147(6):607-609.

179. Thomas IH, et al. Neonatal diabetes mellitus with pancreatic agenesis in an infant with homozygous IPF-1 Pro63fsX60 mutation. Pediatr Diabetes. 2009;10(7):492-496.

180. Schwitzgebel VM, et al. Agenesis of human pancreas due to decreased half-life of insulin promoter factor 1. J Clin Endocrinol Metab. 2003;88(9):4398-4406.

181. Nicolino M, et al. A novel hypomorphic PDX1 mutation responsible for permanent neonatal diabetes with subclinical exocrine deficiency. Diabetes. 2010;59(3):733-740.

182. Edghill EL, et al. Sequencing PDX1 (insulin promoter factor 1) in 1788 UK individuals found $5 \%$ had a low frequency coding variant, but these variants are not associated with Type 2 diabetes. Diabet Med. 2011;28(6):681-684.

183. Temple IK, et al. Transient neonatal diabetes: widening the understanding of the etiopathogenesis of diabetes. Diabetes. 2000;49(8):1359-1366.

184.Sellick GS, et al. Mutations in PTF1A cause pancreatic and cerebellar agenesis. Nat Genet. 2004;36(12):1301-1305.

185. Hoveyda N, et al. Neonatal diabetes mellitus and cerebellar hypoplasia/agenesis: report of a new recessive syndrome. JMed Genet. 1999;36(9):700-704.

186. Tutak E, et al. A Turkish newborn infant with cerebellar agenesis/neonatal diabetes mellitus and PTF1A mutation. Genet Couns. 2009;20(2):147-152.

187. Mitchell J, et al. Neonatal diabetes, with hypoplastic pancreas, intestinal atresia and gall bladder hypoplasia: search for the aetiology of a new autosomal recessive syndrome. Diabetologia. 2004;47(12):2160-2167.

188. Chappell L, et al. A further example of a distinctive autosomal recessive syndrome comprising neonatal diabetes mellitus, intestinal atresias and gall bladder agenesis. Am JMed Genet $A$. 2008;146A(13):1713-1717.

189. Martinovici D, et al. Neonatal hemochromatosis and Martinez-Frias syndrome of intestinal atresia and diabetes mellitus in a consanguineous newborn. Eur JMed Genet. 2010;53(1):25-28.

190.Smith SB, et al. Rfx6 directs islet formation and insulin production in mice and humans. Nature. 2010;463(7282):775-780.

191. Sansbury FH, et al. SLC2A2 mutations can cause neonatal diabetes, suggesting GLUT2 may have a role in human insulin secretion. Diabetologia. 2012;55(9):2381-2385.

192.Shaw-Smith C, et al. Recessive SLC19A2 mutations are a cause of neonatal diabetes mellitus in thiamine-responsive megaloblastic anaemia. Pediatr Diabetes. 2012;13(4):314-321.

193. Touati A, et al. Transient neonatal diabetes mellitus and hypomethylation at additional imprinted loci: novel ZFP57 mutation and review on the literature. Acta Diabetol. 2019;56(3):301-307.

194. Yilmaz Agladioglu S, et al. Urinary C-Peptide/ 
creatinine ratio can distinguish maturity-onset diabetes of the young from type 1 diabetes in children and adolescents: a single-center experience. Horm Res Paediatr. 2015;84(1):54-61.

195. Pal A, et al. Evaluation of serum 1, 5 anhydroglucitol levels as a clinical test to differentiate subtypes of diabetes. Diabetes Care. 2010;33(2):252-257.

196. Thanabalasingham $\mathrm{G}$, et al. A large multi-centre European study validates high-sensitivity C-reactive protein (hsCRP) as a clinical biomarker for the diagnosis of diabetes subtypes. Diabetologia. 2011;54(11):2801-2810.

197. McDonald TJ, et al. High-sensitivity CRP discrim- inates HNF1A-MODY from other subtypes of diabetes. Diabetes Care. 2011;34(8):1860-1862.

198. Owen KR, et al. Assessment of high-sensitivity $\mathrm{C}$-reactive protein levels as diagnostic discriminator of maturity-onset diabetes of the young due to HNF1A mutations. Diabetes Care. 2010;33(9):1919-1924.

199. Fu J, et al. Using clinical indices to distinguish MODY2 (GCK Mutation) and MODY3 (HNF1A Mutation) from Type 1 diabetes in a young Chinese population. Diabetes Ther. 2019;10(4):1381-1390.

200.Juszczak A, et al. Plasma fucosylated glycans and c-reactive protein as biomarkers of HNF1A-
MODY in young adult-onset nonautoimmune diabetes. Diabetes Care. 2019;42(1):17-26.

201. Besser RE, et al. Urinary C-peptide creatinine ratio is a practical outpatient tool for identifying hepatocyte nuclear factor $1-\alpha /$ hepatocyte nuclear factor 4- $\alpha$ maturity-onset diabetes of the young from long-duration type 1 diabetes. Diabetes Care. 2011;34(2):286-291.

202.Fendler W, et al. HDL cholesterol as a diagnostic tool for clinical differentiation of GCK-MODY from HNF1A-MODY and type 1 diabetes in children and young adults. Clin Endocrinol (Oxf). 2011;75(3):321-327. 